\title{
Creep test rig for cantilever beam: Fundamentals, prospects and present views
}

\author{
M. R. M. Asyraf1 ${ }^{1}$, M. R. Ishak ${ }^{1,2,3,{ }^{\star},}$ S. M. Sapuan ${ }^{4}$, N. Yidris ${ }^{1}$, R. M. Shahroze ${ }^{1}$, A. N. Johari ${ }^{1}$, M. Rafidah ${ }^{5}$ and R. A. Ilyas ${ }^{4}$ \\ 1 Department of Aerospace Engineering, Universiti Putra Malaysia, 43400 UPM Serdang, Selangor, Malaysia \\ Phone: +60397694396; Fax: +60397697125 \\ ${ }^{2}$ Aerospace Malaysia Research Centre (AMRC), Universiti Putra Malaysia, 43400 UPM Serdang, Selangor, Malaysia \\ ${ }^{3}$ Laboratory of Biocomposite Technology, Institute of Tropical Forest and Forest Product (INTROP), Universiti Putra Malaysia, 43400 UPM \\ Serdang, Selangor, Malaysia \\ ${ }^{4}$ Advanced Engineering Materials and Composites Research Centre (AEMC), Department of Mechanical and Manufacturing Engineering, Universiti \\ Putra Malaysia, 43400 UPM Serdang, Selangor, Malaysia \\ ${ }^{5}$ Department of Civil Engineering, Universiti Putra Malaysia, 43400 UPM Serdang, Selangor, Malaysia
}

\begin{abstract}
Cross arms in transmission tower are made up of Chengal wood, which degrade and collapse after a long period of service. This is due to creep deformation, and the rate of degradation is expedited due to exposure to extreme tropical climate. Hence, it is crucial to comprehend the early creep stage, which leads to structural failure. Apart from that, there are several research and industrial application gaps of these cross arms. For instance, creep life analysis of actual cross arms is still unexplored. In this study, the state-of-the-art is related to creep experiments and creep test rig designs, espacially on the creep test of a cantilever beam setup. The experimental methodologies implemented two vital approaches, conventional and accelerated techniques. The specific creep experiments on cantilever beam structure are emphasized and suggested in the manuscript as the building blocks for future design of cantilever creep test rig. This helps to guide future development design of cantilever beam creep test rig by fulfilling the specific criteria related to creep fundamentals, numerical modelling analysis, test operation for data evaluation, and development process. At the end, the challenges and improvements on the criteria existing design of test rigs are elaborated.
\end{abstract}

ARTICLE HISTORY

Revised: $4^{\text {th }}$ Apr 2020

Accepted: $15^{\text {th }}$ Apr 2020

\section{KEYWORDS}

Creep; material characterization; anisotropic material; cantilever beam; long term durability; test rig.

\section{INTRODUCTION}

Electrical transmission line system encompasses various components, namely electrical cable conductors, insulators, transmission tower, foundations, and earthling systems. The system usually carries electrical signals via cables lifted by transmission towers from power generators to supply to the consumers. Transmission towers hold cables by lifting them above the ground level using extended arm structures, namely cross arms [1,2]. Previously, a wooden cross arms had been introduced in Malaysian electrical system using Chengal (Neobalancarpus heimii) hardwood due to their mechanical performance [3]. However, some studies stated that the matured Chengal wood would experience severe deformation, which lead to internal cracking subsequently failure after 20 years of service [4]. This happened due to natural based material such as natural fibre and wood manifested creep issues when serve in prolonged period [5-7]. Thus, a resolution have to be made to substitute the current wooden cross arm with glass fibre based composite cross arm [8-14]. It is estimated that fibre reinforced polymer composites will expand their usage in the near future due to the advantages offered by these materials, i.e. low maintenance cost, corrosion resistance, low weight, low density, chemical resistance, durable, design flexibility, high thermal and strength properties [15-28]. The glass fibre composite has many applications including in energy generation $[29,30]$ to household [31] products since they has higher in mechanical performance [3234].

Various simulation modelling analyses were carried out to find the theoretical data of the properties of composite cross arms. These include the study on the computation simulation (finite element analysis), which covers the topics of effect of static load [35], the stacking sequence of composite [36], and different material and configuration [37]. Apart from that, numerous researches were executed on coupon strip size to evaluate the long-term mechanical properties of GFRP composite in various types of setups [38]. Coupon tests are performed in tensile mode [39] and flexural mode [40] to forecast the GFRP of creep life. Thus, this shows that most researches on the GFRP cross arms currently cover the numerical and experimental aspects of coupon scale.

Despite various discussions on simulation modelling analyses and coupon experiments, no studies on evaluation of creep behaviours for actual size of cross arm members are found in the literature. Moreover, the application of glass fibre based composite cross arms in transmission towers is still a relatively new product in the market compared to conventional type (wood and galvanised steel) [41, 42]. Subsequently, there is a need to perform mechanical analysis on actual composite cross arms to have a holistic view of their properties. To perform mechanical analysis, a new creep test rig is 
required to be developed to cater to the actual sized composite cross arms. Conducting creep experiments on a full-scale cross arm would aid to remove the exaggerated factors implemented at a small scale test (coupon) [43]. Thus, a review on the creep fundamentals, mechanisms of existing test rigs and theoretical backgrounds of cantilever beam are those essential topics in order to provide a valid background in developing a new test rig for full-scale size cross arm. This goals assists in the development of appropriate test rig for cross arm structure in clarifying its creep properties.

This manuscript is aimed at presenting a state-of-the-art review of theoretical background of creep and available creep testing operations conducted by previous researchers. Since the subject is vast and numerous of published literatures are already available, it is difficult to conduct this review comprehensively. Thus, this review collects those particular emphasis on the development of creep test rig for cantilever beam structure focusing on cross arm. Eventually, possible problems can be catered more deliberately in the future.

\section{FUNDAMENTALS AND PRINCIPLES OF CREEP}

Creep, or in other word, cold flow, is the possibility of solid material which deforms permanently influenced by continuous constant mechanical stresses. The creep would distort the size and shape of material, as it is exposed to continuous loading for a long time period [44]. In this investigation, creep evaluation was carried out by magnifying two main variables, which are creep strain and time period. The relationship of creep strain and time period depends on each other, due to Hooke's law principle of material. Since the cross arm is made of viscoelastic material such as wood (conventional) and composite (current), the behaviour of the material is much related to this theory. This principle allows the material to experience elastic behaviour, as a force is acted on it until the yield limit. Commonly, this material stores elastic energy as the shape moves towards the force exerted, and later, it tends to revert the shape into its original form as the stress is removed. As the force applied on the material structure exceeds the elastic limit, the material will exhibit a plastic behaviour causing the stress concentrated to be hardened. Later, it could lead to rupture and failure [45, 46]. Other than that, the material experiences liquid-like behaviour in elevated temperature. This condition can be classified as viscoelastic behaviour as deformation happens in temperature-dependent function [40, 47, 48].

Basically, an anisotropic material, especially polymeric composite, probably consumes more than a decade to rupture. Hence, it is not practical to characterise the creep behaviour of a material which consumes a complete cycle of test. To obtain similar creep data, an accelerated creep mode is introduced by implementing high temperature condition to shorten the time [49]. In this section, the prediction of creep behaviour can be determined using both conventional (timedependent) and accelerated (temperature-dependent) approaches. Figure 1 shows the classification of creep methodologies implemented in any mode of testing. Table 1 depicts the overview of literature on two modes of creep tests with their specifications.

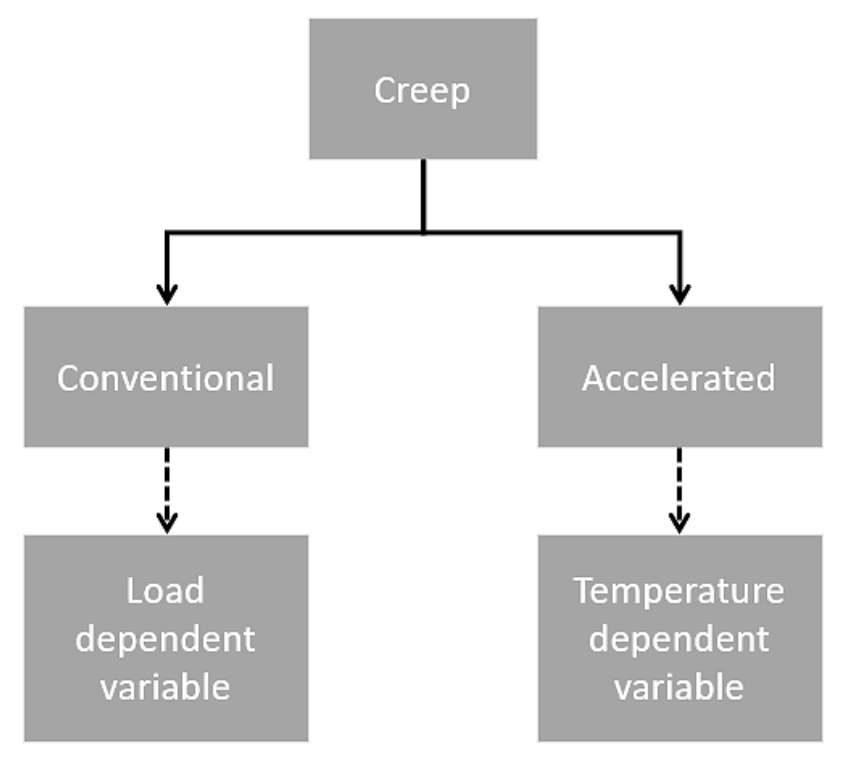

Figure 1. Schematic diagram of classification of creep methodologies. 
Table 1. Overview of creep test with accelerated and conventional methods.

\begin{tabular}{|c|c|c|c|c|c|}
\hline Ref & Creep methods & Mode & Instruments & $\begin{array}{l}\text { Material and } \\
\text { methods }\end{array}$ & Results and discussion \\
\hline$[50]$ & Conventional & $\begin{array}{l}\text { Stress- } \\
\text { time } \\
\text { variable }\end{array}$ & $\begin{array}{c}\text { Implement } \\
\text { extensometer } \\
\text { and constant } \\
\text { loads }\end{array}$ & $\begin{array}{l}\text { - Effect of } \\
\text { various types of } \\
\text { epoxy on glass } \\
\text { and carbon } \\
\text { fibre using } \\
\text { tensile mode } \\
\text { - Apply } 80 \% \text { of } \\
\text { UTS }\end{array}$ & $\begin{array}{l}\text { - Carbon-EP50 } \\
\text { composite is the best } \\
\text { long-term creep } \\
\text { properties up to } 30 \\
\text { hours and highest of } \\
\text { creep modulus } \\
\text { - The rupture facets of } \\
\text { composites } \\
\text { experienced toward } \\
\text { direction of loading, } \\
\text { which create voids on } \\
\text { their laminate interface }\end{array}$ \\
\hline$[51]$ & & & & $\begin{array}{l}\text { - Comparison } \\
\text { (Incorporation } \\
\text { of WPC) CEC } \\
\text { with LVL in 3- } \\
\text { point bending at } \\
30 \%, 40 \% \text { and } \\
50 \% \text { of UFS }\end{array}$ & $\begin{array}{l}\text { - Creep responses of } \\
\text { CEC was better than } \\
\text { LVL } \\
\text { - Higher creep resistance } \\
\text { because of the } \\
\text { contribution of the } \\
\text { WPC shell }\end{array}$ \\
\hline$[52]$ & Accelerated & TTSP & $\begin{array}{l}\text { Apply inside } \\
\text { DMA machine }\end{array}$ & $\begin{array}{l}\text { - The impact of } \\
\text { treated jute fibre } \\
\text { in Jute-PP } \\
\text { composites } \\
\text { using DMA } \\
\text { machine } \\
\text { - Analyse using } \\
\text { master curve to } \\
\text { predict creep } \\
\text { response and } \\
\text { life }\end{array}$ & $\begin{array}{l}\text { - Jute-PP composite is } \\
\text { lower creep than PP } \\
\text { laminate due to creep } \\
\text { resistance from } \\
\text { reinforcement of jute } \\
\text { fibre } \\
\text { - From master curve, the } \\
\text { addition of jute fibre in } \\
\text { composite is } 15 \% \\
\text { lower than } \\
\text { unreinforced PP at } \\
\text { approximately } 25 \text { days } \\
\text { of creep life }\end{array}$ \\
\hline [53] & & TTSSP & & $\begin{array}{l}\text { - Flexural creep } \\
\text { properties on } \\
\text { discontinuous } \\
\text { thermoplastic } \\
\text { composites } \\
\text { - To construct } \\
\text { master curve, } \\
\text { stress variable } \\
\text { shifted } \\
\text { vertically along } \\
\text { with } \\
\text { temperature } \\
\text { variable shifted } \\
\text { horizontally } \\
\end{array}$ & $\begin{array}{l}\text { - All discontinuous } \\
\text { thermoplastic } \\
\text { composites performed } \\
\text { in non-linear } \\
\text { viscoelasticity } \\
\text { properties and good in } \\
\text { creep resistance with } \\
\text { static flexural yield } \\
\text { strength. } \\
\text { - The steepness of } \\
\text { accelerated creep is } \\
\text { dependable on the } \\
\text { temperature and stress } \\
\text { load variables. }\end{array}$ \\
\hline
\end{tabular}

\section{Conventional Creep Approach}

One of the creep approaches uses a series of load values as the manipulated variable in order to characterise the creep properties of the cantilever beam structure. Commonly, the process of conventional creep test takes up around a minimum of 1,000 hours of test operation [54]. However, the extrapolation of the data obtained from the experiment is uncertain throughout the test due to external factors such as humidity, temperature, and vibration. In order to evaluate the actual creep with real external conditions, this is the most reliable method in order to estimate the long-term behaviour of a material [55-57].

To justify the statement above, a general mathematical equation regarding load versus time as variables is drawn in Eq. (1). This equation derives the creep compliance of load based dependent function. 


$$
S(t)=\frac{\varepsilon(t)}{\sigma}
$$

where, $S(t)$ is creep compliance as a function of time, $\varepsilon(t)$ is strain deformation as a function of time, and $\sigma$ is the stress applied on the specimens.

Many researches have been carried out to examine the creep pattern of material by using load based approach (conventional method). Basaid et al. (2017) [50], studied the effect of matrix type on creep behaviour at $80 \%$ loads of ultimate tensile strength of two laminated composites at different fibre (carbon and glass) and matrix (various types of epoxy) systems. The obtained results presented that no creep rupture happened in less than 4 hours of creep operation for carbon-epoxy INJ composites at 80\% of ultimate tensile strength. Carbon-EP50 composite performed the best long-term creep properties up to 30 hours, and executed the highest creep modulus compared to other laminated composites. The findings also explained that the rupture facets of composites were experienced towards the direction of loading, which created voids on their laminated interfaces.

In other works, conventional creep method has also been done by Fu et al. (2020) [51], by performing the comparison of flexural creep properties of laminated veneer lumber (LVL) and wood-plastic composites (WPC). The creep properties of the LVL and CEC were compared at different levels of stresses $(30 \%, 40 \%$, and $50 \%$ of ultimate flexural strength) at room temperature. Based on the results obtained, the creep responses of CEC were better than LVL. This showed that the average failure strain increased by $53.9 \%$ relative to LVL. Lower strain and compliance rates for the CEC at the viscoelastic stage indicated higher creep resistance because of the contribution of the WPC shell.

\section{Accelerated Creep Approach}

In the previous section, accelerated creep evaluates creep properties of a material by implementing elevated temperature to predict the material's service life. The technique evaluates a series of temperature as a dependent variable to shorten the time period in order to represent creep. In this method, the accurate technique used by various researchers to specify the method is time-temperature superposition principle (TTSP). The TTSP elaborates its principle by plotting master curve based on a series of increment temperature. In this case, the principle applied a shifting parameter $\left(a_{t}\right)$ to build the master curve in order to predict the creep life and properties [44, 61]. A logarithmic response of time at a particular temperature can be shifted horizontally along the time axis, and it was completed to overlap with other neighbouring temperature. The shift parameter $\left(a_{t}\right)$ can be evaluated by dividing the generated time steps for a temperature $(t)$ with the reduced time corresponding to a reference temperature $\left(t_{r}\right)$ as shown in Eq. (2).

$$
a_{t}=\frac{t}{t_{r}}
$$

where, $a_{t}$ is shifting parameter; $t$ is generated time steps for a temperature; and $t_{r}$ is duced time corresponding to a reference temperature.

Many researches have been carried out using temperature-based approach, which is TTSP, to examine the creep properties of a specific material. According to Chandekar et al. (2016) [52], they studied the flexural creep properties of treated sodium hydroxide of jute fibre reinforced polypropylene (PP) composites using TTS principle. The accelerated creep study was evaluated in dynamic mechanical analyser (DMA) to predict the long-term creep properties. In the test, the creep compliance and master curve were conditioned at $50^{\circ} \mathrm{C}$ and $1 \mathrm{MPa}$ of constant stress for 30 minutes, and compared between pure PP and 25\% jute-PP composite. The results showed that jute-PP composite was a lower creep compared to PP laminate due to creep resistance from the reinforcement of jute fibre. Moreover, the master curve projected by Rheology Advantage software predicted that jute-PP composite was $15 \%$ lower than unreinforced PP at approximately 25 days of creep life.

Other than that, Chevali et al. (2009) [53] conducted a research on flexural creep properties on discontinuous thermoplastic composites including nylon 6/6, polypropylene and high-density polyethylene long fibre thermoplastic (LFT) with a series of applied stress. The test implemented time-temperature-stress superposition (TTSSP) procedure, where the stress variable shifted vertically along with temperature variable, which shifted horizontally. The outcomes of the experiment displayed that all discontinuous thermoplastic composites performed in non-linear viscoelasticity properties, and had good creep resistance with static flexural yield strength. In addition, the TTSSP model exhibited that the there was a characteristic curvature at the higher end of the master curve, which showed that the steepness of accelerated creep was dependable on the temperature and stress load variables.

\section{CREEP NUMERICAL MODELS}

Various researchers on creep experiments have been carried out by evaluating the numerical models in order to estimate long-term mechanical properties of a material [58-60]. These numerical models are categorized into two types, namely empirical and physical models, as shown in Figure 2. The empirical models, commonly known as power models, 
are comprised of Findley's Power model and Norton Bailey model. Meanwhile, the physical model used to interpret the creep behaviour is Burgers model [61].

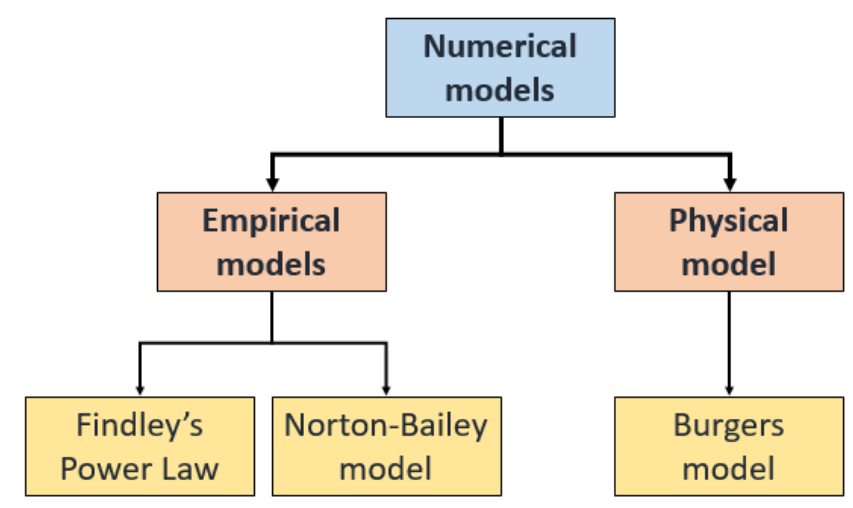

Figure 2. Classification of numerical models for creep analysis.

\section{Burger Model}

The Burgers model is a creep model that implements the generalisation for polymer composites between creep behaviour and structure [62, 63]. It is classified as a physical model since it applies a series of spring and dashpot arrangement to explain the creep phenomenon. A total strain experience in a specific time is usually divided into three main components. These components, namely elastic strain (Maxwell spring), viscoelastic strain (Kelvin's dashpot element), and viscous strain (Kelvin-Voight element), are the strains experienced by a material [64, 65]. The creep experiment data based on Burgers model would provide a reliable creep speculation according to their time-dependent responses. Figure 3 displays a schematic diagram to visualise the Burgers model when applied in creep evaluation.

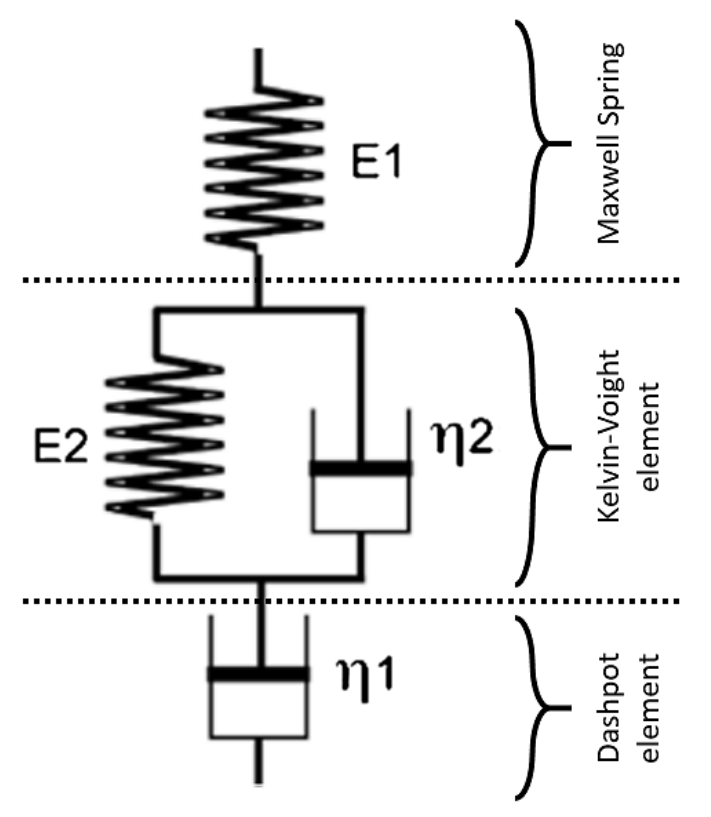

Figure 3. Schematic diagram to explain Burger model.

This model can be exhibit as follows:

$$
\varepsilon(\mathrm{t})=\varepsilon_{e}+\varepsilon_{d}[1-\exp (-\mathrm{Ct})]+\varepsilon_{v} \mathrm{t}
$$

The parameter from Eq. (3) contains four independent variables which can be indicated for Burgers model. In general, the stresses applied should remain constant for the properties of material inherited through viscosity and elastic modulus. 


\section{Findley Power Law Model}

Findley's power model is commonly used to evaluate the prediction of transient creep strain along elastic strain which affects creep over time [66]. However, the model applications are limited due to the direct and straightforward numerical calculation that is implemented universally to any system. This is due to lack of deliberation on dimensional changes of material during the testing in conjunction to the model [67-69]. The model also relates to the material properties such as molecular mobility in the microscopic level to the creep strain. The model is signified in Eq. (4) [70] as displayed:

$$
\varepsilon(t)=K t^{n}+\varepsilon_{e}
$$

where, $\varepsilon_{\mathrm{e}}$ is the stress-dependent instantaneous elastic strain; $K$ is the stress-dependent coefficient; and $n$ is the stressindependent material constant.

\section{Norton-Bailey Model}

Norton-Bailey model or Norton's power law model is an empirical model, which describes the secondary creep deeper. The model aids researchers and engineers to forecast the creep damage properties in terms of crack initiation and crack growth [71]. Furthermore, the model also provides a more efficient elaboration on the primary and secondary relationships of creep under constant load and the influence of temperature as shown in Eq. (5) [72].

$$
\varepsilon(t)=m \sigma^{k} \mathrm{t}^{n}
$$

where, $m, k, n$ are constants for temperature. Many studies also show that temperature is measured moderately constant [73].

\section{CANTILEVER BEAM CONCEPTS}

Since the cross arm component obeys the principle of cantilever beam structure, a solid mechanics analysis has to be developed in order to analyse the creep behaviour. In this case, the Hooke's law principle is used since the material of cross arm (wood and composite) permits elastic properties. The Hooke's law [74] in the stress-strain relationship: $F=k x[F$ is the elastic force $(\mathrm{N}), k$ is an elastic coefficient $(\mathrm{N} / \mathrm{m})$, and $x$ is the elastic deformation $(\mathrm{m})]$. The relationship can also be described as:

$$
\sigma=E \varepsilon
$$

where, $\sigma$ is the applied stress; $E$ is the elastic modulus; and $\varepsilon$ is the elastic strain.

For bending analysis of a cantilever beam, it can be expected that the extension occurring at the upper part is tension, whereas compression occurs at the bottom part of the beam. The cantilever beam has a non-uniform stress distribution depending on the thickness and length of the beam. However, for a wooden material, it is already established that the material exhibits a non-uniform density profile, which contributes to static material properties [74, 75]. Hence, in order to assume the viscoelastic properties of wood, the identification of wood thickness is considered a vital factor.

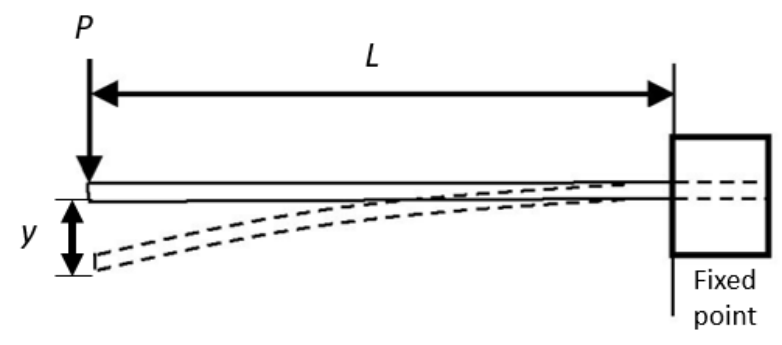

Figure 4. Cantilever beam structure with applied force at the end of the beam.

The beam deflection (Figure 4) that occurred along the beam was determined based on Eq. (7):

$$
y=\frac{P L^{3}}{3 E_{e} I}=\frac{4 P L^{3}}{3 E_{e} b h^{3}}
$$

where, the beam was deflected at a known value of $y$ with measured load of $P$; and the static elastic modulus $\left(E_{e}\right)$ can be determined by rearranging Eq. (7): 


$$
E_{e}=\frac{4 P L^{3}}{y b h^{3}}
$$

where, $y$ is the deflection at the beam $(\mathrm{m}) ; E_{e}$ is the static elastic modulus $\left(\mathrm{N} / \mathrm{m}^{2}\right) ; P$ is the exerted force on the beam $(\mathrm{N})$; $L$ is the total cantilever beam length (m); and $I$ is the moment inertia of square bar $\left(\mathrm{m}^{4}\right)\left(I=b h^{3} / 4\right.$, where $b$ and $h$ are the width and thickness of the beam, respectively, in unit $\mathrm{m}$ ).

The maximum bending stress was forecasted by implementing the known deflection (y) inside Eq. (9) [76]. In general, the beam experiences the highest stress at the fixed point $x=0$, whereas the minimum stress is exhibited at the loading end of the beam, $x=L$. At this point of view, a cantilever beam displayed a decreasing of stress concentration from the fixed point to the load point, as shown in Figure 5. From this statement, it can be deduced that the average stress of the whole beam is half of the maximum stress exerted.

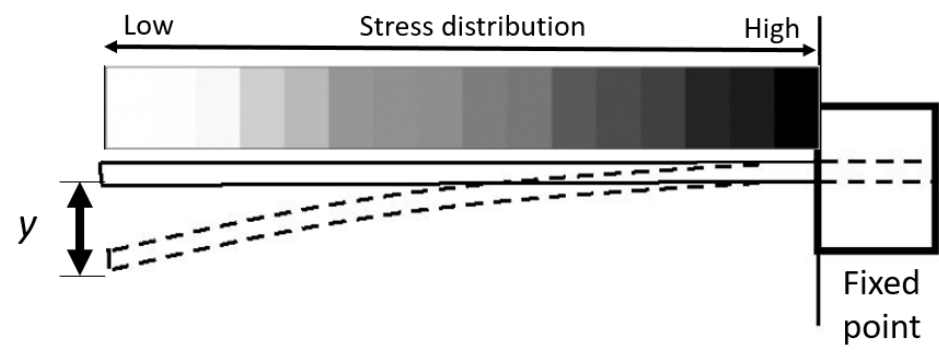

Figure 5. Stress distribution along a cantilever beam.

$$
\begin{gathered}
\sigma=\frac{P(L-x) \frac{h}{2}}{I}=\frac{6 P(L-x)}{b h^{3}} \\
\sigma_{\text {max }}=\frac{6 P(L)}{b h^{2}} ; x=0, \sigma_{\text {min }}=0 ; x=L, \text { and } \sigma_{\text {ave }}=\frac{1}{2} \times \frac{6 P(L)}{b h^{2}}=\frac{3 P(L)}{b h^{2}}
\end{gathered}
$$

The specific strain at each location is given by Eq. (10), which implements the Hooke's law equation.

$$
\varepsilon(t)=\frac{\sigma_{n}}{E_{e}}=\left[\frac{\left(\frac{3 P(L)}{b h^{2}}\right)}{\left(\frac{4 P_{\max } L^{3}}{y b h^{3}}\right)}\right]
$$

where, $\varepsilon_{t}$ is the specific strain; $\sigma_{n}$ is specific stress; and $E_{e}$ is the static elastic modulus at the specific point of cross arm.

The long-term behaviours of cantilever beam follow the Hooke's law for material engineering. In this case, several studies have implemented the concept of cantilever beam mechanics in order to evaluate the creep properties and life estimation of the beam. Thus, the subsequent section explains several experiments related to cantilever beam in order to study the creep behaviour of anistropic material.

\section{PREVIOUS CREEP EXPERIMENTS ON CANTILEVER BEAM SPECIMENS}

Several literatures have reported on creep cantilever beam tests on composite materials under uniaxial force. Most creep tests using cantilever mode were done under controlled environment [77]. The general concept of cantilever beam mode test is where the specimen is held using stand holder with load hanger attached at the other end [78].

Wong and Shanks [79] carried out an experiment on flax-polylactic acid (PLA) composite with different fibre treatments and additives such as glyceryl triacetate (GTA), triethyl citrate (TEC), tributyl citrate (TBC), poly(ethylene glycol) (PEG), hyperbranched polyester (HBP) with 32hydroxyl functionality, and thiodiphenol (TDP). The test was executed using three different stress concentrations $(5.0,10.0$, and $15.0 \mathrm{MPa})$ in the mode of cantilever beam as shown in Figure 6. The specimen size was set at $6 \mathrm{~mm} \times 18 \mathrm{~mm}$ x $1.5 \mathrm{~mm}$. The test was also held in Dynamic Mechanical Analyser (DMA) using static mode condition. Initially, the stress was applied for 10 minutes before released for recovery period of around 20 minutes. The results displayed that the inclusion of additives would increase the resistance of creep compared to pure composite. This occurred since plasticised TDP composites experienced reduction in the viscous flow contribution, and an increase in the viscoelastic deformation. 


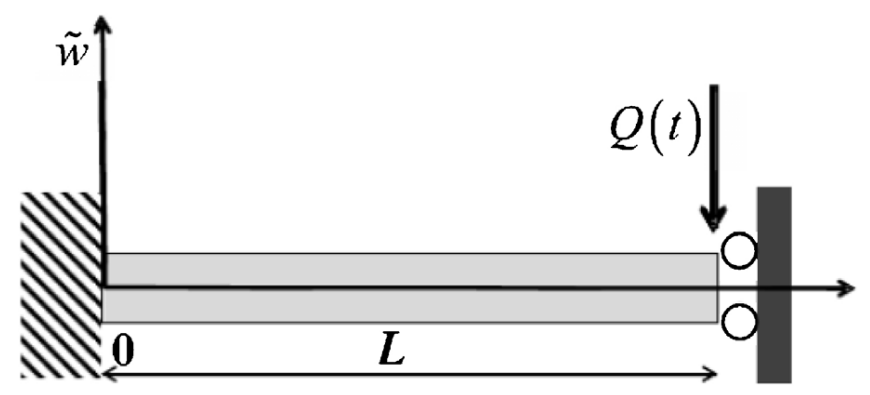

Figure 6. Schematic diagram of flax-PLA composites cantilever beam [79].

Hunt et al. (2015), employed a simple cantilever beam (SCB) structure that was vertically hung and fabricated from high-density fibreboard (HDF), medium-density fibreboard (MDF), and particle board (PB) to analyse its creep behaviour [74]. The authors applied bending load on vertical beam specimens, and recorded its changes in deformation. The test device was divided into two parts: mechanical structure and data processing. The changes of the displacement happening at the beam end were logged by laser displacement gauge, which was connected directly to the computer. The results showed that the cantilever beam could be used to measure the relaxation rates of composite structure. Thus, the study exhibited the potential of using a mechanistic approach to explain the behaviour of cantilever with constant displacement relaxation. Figure 8 shows the component diagram of vertical cantilever beam test used by the authors.

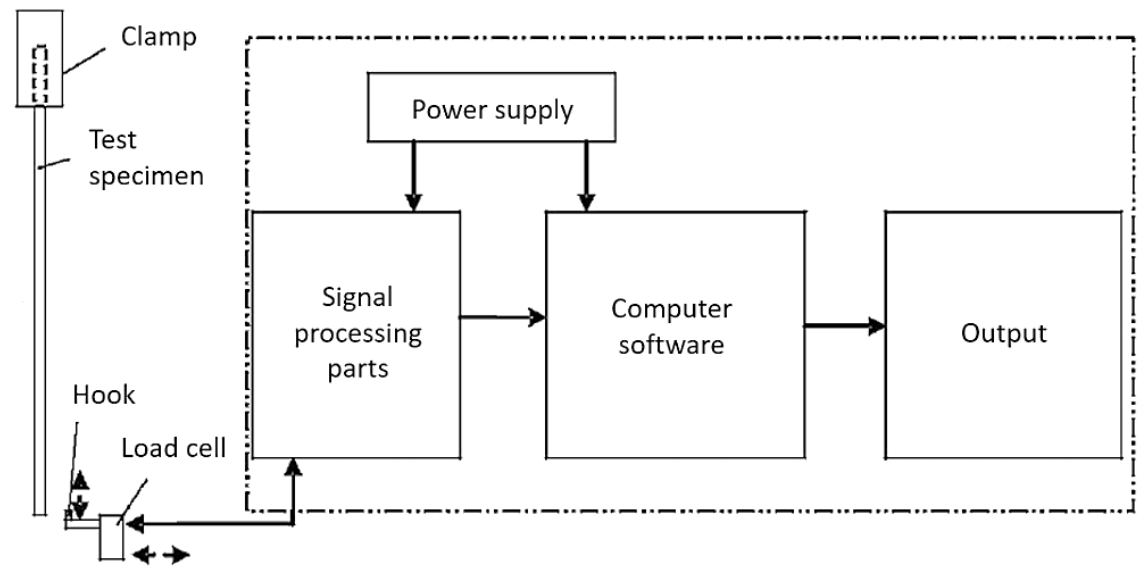

Figure 8. Components diagram of cantilever beam test.

Various cantilever beam tests on anisotropic material have been carried out in single beams in small coupon scale size specimens. However, no study has been carried out on the actual structure, especially on cross arms. Thus, the concept of cantilever beam of SBC coupon scale can be implemented to cross arm structure. In conjunction to the previous statement, there are other types and modes of creep tests which are widely used by other researchers. Hence, the following section will further elaborate the current creep test rigs used based on previous literatures.

\section{CURRENT CREEP TEST RIGS}

In the past few decades, creep studies of anisotropic material have been progressive in the field of coupon scale analysis in order to characterize the long-term mechanical properties [80, 81]. This study has continuously grown in the application of composite material in heavy-duty structural products, such as automotive antiroll bar [82], car front hood [83], automotive spoiler [84], fire extinguisher tank [85], marine propellant shaft [86] and flight wing components [87]. This shows that the test rigs are essential equipment to analyse long-term creep properties of polymeric material before being applied in real life. The performance of test rigs has to be identified on the parameters including the design, operation procedure, and working environment. Currently, there are three main setups used in order to conduct creep, which are compression, tensile, and flexural modes [61]. Hence, this section elaborates several test rigs used by previous researchers, and the results obtained from the experiments they conducted. Table 2 shows the summary on the three major creep operations of anistropic material which are flexural, tensile and compression. 
Table 2. Summary of previous creep test rigs with their results.

\begin{tabular}{|c|c|c|c|c|c|}
\hline Ref & Creep methods & Mode & Instruments & Material and methods & Results and discussion \\
\hline$[88]$ & Compression & $\begin{array}{c}\text { Stress- } \\
\text { time } \\
\text { variable }\end{array}$ & $\begin{array}{l}\text { Use custom creep } \\
\text { fixture } \\
\text { extensometer } \\
\text { with } 3 \text { specimens } \\
\text { can run } \\
\text { simultaneously }\end{array}$ & $\begin{array}{l}\text { - Study compressive } \\
\text { creep of pultruded E- } \\
\text { glass fibre reinforced } \\
\text { vinylester from I-shaped } \\
\text { beam. } \\
\text { - Implement } 20 \% \\
(65 \mathrm{MPa}), 40 \%(129 \\
\mathrm{MPa}) \text { and } 60 \%(194 \\
\mathrm{MPa}) \text { from UCS. }\end{array}$ & $\begin{array}{l}\text { - Sustained stress level } \\
\text { should not be exceed } \\
33 \% \text { for pultruded GFRP } \\
\text { composite. } \\
\text { - Findley power law } \\
\text { was suitable to forecast } \\
\text { the creep properties of } \\
\text { the material loaded to } \\
60 \% \text { of its ultimate } \\
\text { strength. }\end{array}$ \\
\hline [89] & & TTSSP & $\begin{array}{l}\text { - Use Dynamic } \\
\text { Mechanical } \\
\text { Analyser (DMA) } \\
\text { with } \mathrm{P}_{2} \mathrm{O}_{5} \text { gas } \\
\text { environment } \\
\text { - Moisture } \\
\text { content of the } \\
\text { conditioned wood } \\
\text { sample was as } \\
\text { low as } 0.6 \% \text {. }\end{array}$ & $\begin{array}{l}\text { - Conduct compressive } \\
\text { creep on different section } \\
\text { (tangential, longitudinal } \\
\text { and cross) of Chinese fir } \\
\text { under elevated } \\
\text { temperature } \\
\text { - Implement TTSSP at } \\
\text { temperature at } 140-220 \\
{ }^{\circ} \mathrm{C} \text { and stress at } 0.03-0.15 \\
\mathrm{MPa} \\
-\quad \text { Specimen dimension: } \\
10 \times 10 \times 10 \mathrm{~mm}^{3}\end{array}$ & $\begin{array}{l}\text { - TSSP and TTSSP } \\
\text { were feasible to predict } \\
\text { compressive creep of } \\
\text { Chinese fir wood with } \\
180^{\circ} \mathrm{C} \text { as reference } \\
\text { temperature. } \\
\text { - Heat and stress } \\
\text { together would } \\
\text { accelerate the crack and } \\
\text { rupture of the cell wall } \\
\text { especially above } 200^{\circ} \mathrm{C} \\
\text { and above } 0.09 \mathrm{MPa}\end{array}$ \\
\hline$[90]$ & Tensile & TTSP & $\begin{array}{l}\text { - Consist of } \\
\text { heat chamber in } \\
\text { the creep jig up to } \\
1000^{\circ} \mathrm{C} \\
\text { - Use grip } \\
\text { made up Nickle } \\
\text { alloys }\end{array}$ & $\begin{array}{l}\text { - Study the capability } \\
\text { of composite laminates } \\
\text { up to } 1000^{\circ} \mathrm{C} \text { along long- } \\
\text { term loading period } \\
\text { - A test validation was } \\
\text { run by using polysialate } \\
\text { composite }\end{array}$ & $\begin{array}{l}\text { - Polysialate composite } \\
\text { failure strain increases } \\
\text { from approximately } 1.0 \text { - } \\
1.3 \% \text { whereby strength } \\
\text { decreases from } 288 \mathrm{MPa} \\
\text { to } 213 \mathrm{MPa} \text { in } \\
\text { temperature ranges from } \\
0-760{ }^{\circ} \mathrm{C}\end{array}$ \\
\hline [91] & & TTSP & $\begin{array}{l}\text { - Consist of } \\
\text { thermal chamber } \\
\text { and temperature } \\
\text { relay (control } \\
\text { heat) in the creep } \\
\text { jig } \\
\text { - Also consist } \\
\text { of clamping } \\
\text { system (lower } \\
\text { and upper } \\
\text { clamps) to grip } \\
\text { the specimen } \\
\text { inside the } \\
\text { chamber }\end{array}$ & $\begin{array}{l}\text { - Study the composite } \\
\text { laminate in tensile force } \\
\text { action } \\
\text { - The temperature } \\
\text { chamber has an } \\
\text { application range up to } \\
170{ }^{\circ} \mathrm{C} \\
\text { - } \quad \text { Temperature is } \\
\text { regulated by } \\
\text { thermocouple, which } \\
\text { later carried out } \\
\text { LabVIEW software }\end{array}$ & $\begin{array}{l}\text { - Temperature- } \\
\text { dependent properties } \\
\text { depending on Arrhenius } \\
\text { equation (explain the } \\
\text { activation energy along } \\
\text { with the energy of C-C } \\
\text { bonds scission) } \\
\text { - Non-recoverable } \\
\text { deformations happened } \\
\text { through temperature } \\
\text { which possesses during } \\
\text { the steady state creep } \\
\text { process }\end{array}$ \\
\hline [92] & & $\begin{array}{l}\text { Stress- } \\
\text { time } \\
\text { variable }\end{array}$ & $\begin{array}{l}\text { - Use custom } \\
\text { creep tensile jig } \\
\text { along with load } \\
\text { hanger at the end } \\
\text { - Implement } \\
\text { extensometer } \\
\text { which directly } \\
\text { recorded by } \\
\text { computer }\end{array}$ & $\begin{array}{l}\text { - Effect of GFRP rebar } \\
\text { on } 10 \%, 20 \%, 40 \%, 60 \% \\
\text { and } 80 \% \text { from average } \\
\text { UTS } \\
\text { - Conducted in } \\
\text { laboratory environment } \\
\text { with controlled } \\
\text { temperature }\left(20^{\circ} \mathrm{C}\right) \text { and } \\
\text { humidity }(\mathrm{RH}=50 \%\end{array}$ & $\begin{array}{l}\text { - New relaxation and } \\
\text { creep formulas have been } \\
\text { projected, where adopted } \\
\text { linear logarithmic } \\
\text { equation } \\
\text { - Stress at } 80 \% \text { from } \\
\text { UTS was completely } \\
\text { failed less than } 8 \text { hours } \\
\text { of operation } \\
\text { - GFRP rebar } \\
\text { experience linear } \\
\text { viscoelastic behavior } \\
\text { under service load, } \\
\text { which is less than } 40 \% \\
\text { from maximum tensile } \\
\text { strength }\end{array}$ \\
\hline
\end{tabular}


[93]

$\begin{array}{ccl}\text { Flexural } & \text { Stress- } & - \text { Use custom 4- } \\ \text { time } & \text { point bending } \\ \text { variable } & \text { creep jig along } \\ \text { and } & \text { with load hanger } \\ \text { TTSSP } & \begin{array}{l}\text { at middle of } \\ \text { specimen }\end{array}\end{array}$

Stress-

time

variable

Implement
custom creep jig
along with dial
gauge

- Effect of different
loading stress (26\%, 35\%
and $45 \%$ from UTS) on
GFRP pultruded

- Findley power law equation is well fitted to GFRP pultruded - Creep life prediction obtained for the GFRP is around 11 years for pure bending while 6.5 years for shear bending - Master curve of TTSSP was forecasted well the viscoelastic behavior in long term period

- Comparison of flexural creep properties CEC and LVL at 30\%, $40 \%$ and $50 \%$ of UFS - Implement the test around 1500 hours
- Findley power law model was the suited as compared to Burger model and Norton-Bailey model.

- CEC is highly potential to be used as durable material in heavy structural application

\section{Compression Creep Test Rigs}

A study done by Scott and Zureick (1998) [88] examined the compression creep properties of material coupon from pultruded E-glass fibre reinforced vinyl ester I-shaped beam using lever arm creep fixture. The experiment was implemented in vertical compressive mode for time duration of up to 10,000 hours. Based on the experiment, three levels of loads were used to evaluate the compressive behaviour of the pultruded composites, which are at $20 \%$ (65MPa), $40 \%$ (129 MPa), and 60\% (194 MPa) from the average ultimate compressive stress. Figure 9 displays a lever arm creep fixture with its schematic drawing in order to implement compression load directly on the specimen coupons. In the test setup as shown in Figure 6, the creep fixture was developed by using structural steel along the application of fulcrum concept by implementing the pillow block roller bearing as fixture component. For safety purpose, the creep fixture was designed to support the load up to a safety factor of 10 . The creep fixture was also able to load three coupon specimens simultaneously, as each coupon had its own set of compressive cages. The components and procedures allowed the creep fixture to be able to transfer the tensile load conducted by lever arm to each coupon as compression actions. The results showed that the Findley power model was used to evaluate the long-term creep behaviour in this study, as the material underwent the primary creep. The Findley power law was suitable to forecast the creep properties of the material loaded to $60 \%$ of its ultimate strength for a 5000 hours of operation. Hence, the finding led to a conclusion where the sustained stress level should not exceed 33\% in order to guarantee the Findley model provided a valid description of the GFRP composite behaviour. Apart from that, the value for time-dependent reduction factor differed from the predicted using the experimental data by a range of $15 \%$ to $27 \%$ at time of 75 years, which showed the model was more practical for designers. 


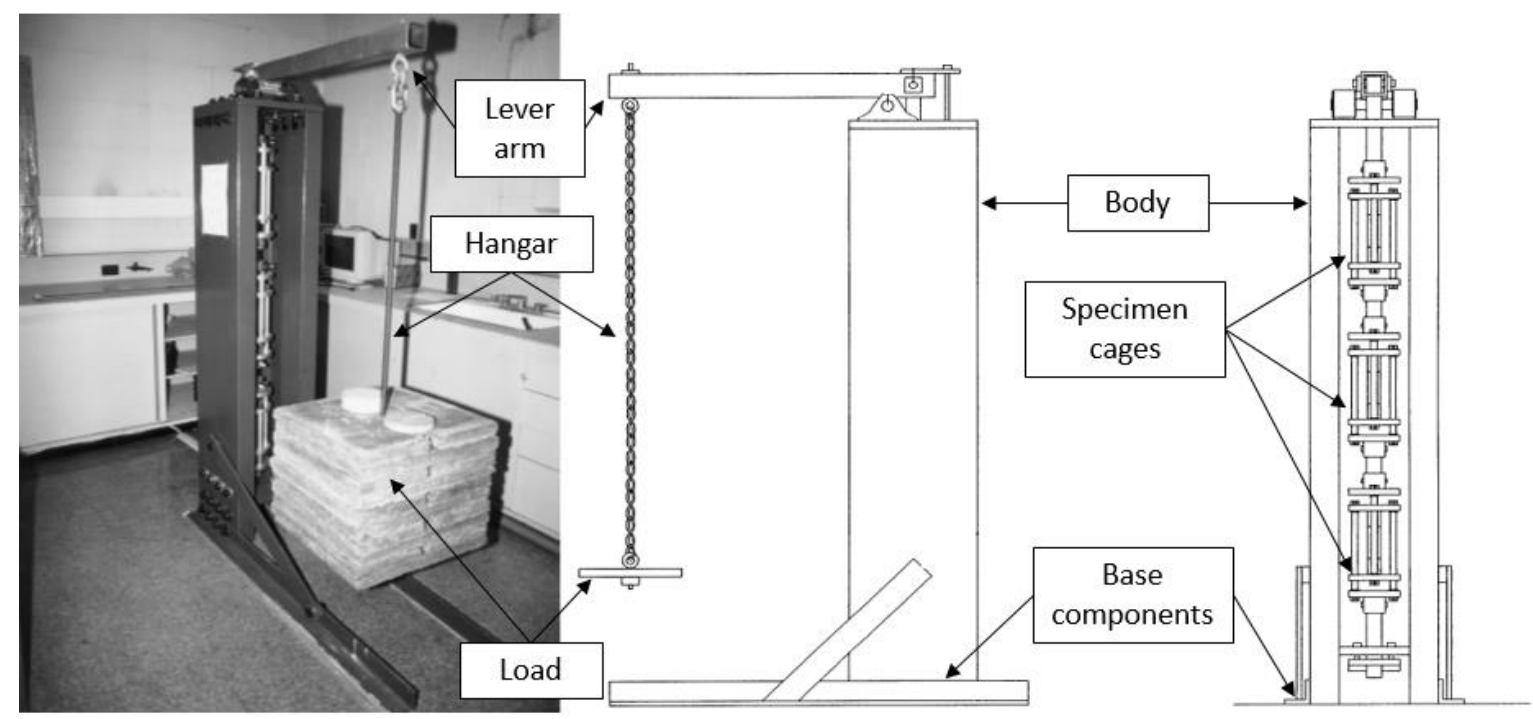

Figure 9. Components diagram of cantilever beam test.

Based on Wang et al. (2020) [89], carried out a research on compressive creep on Chinese fir under elevated temperature. The study focused on predicting long-term viscoelasticity of Chinese at a series of temperature of $140-220^{\circ} \mathrm{C}$, and stresses at 0.03-0.15 MPa. The creep test was conducted on different sections of Chinese fir, which are cross, radial, and tangential with dimension of $10 \times 10 \times 10 \mathrm{~mm}^{3}$. The test was carried out using Dynamic Mechanical Analyser (DMA). Moreover, the $\mathrm{P}_{2} \mathrm{O}_{5}$ gas was conditioned before the experiment started. Creep strain was determined by the compressive deformation, automatically recorded through the device. The moisture content of the conditioned wood sample was as low as $0.6 \%$. The results obtained pointed out that time stress superposition (TSSP) and time-temperature stress superposition (TTSSP) were feasible to predict compressive creep of Chinese fir wood at high temperature range with $180^{\circ} \mathrm{C}$ as reference temperature. The effect of heat and stress together would accelerate the crack and rupture of the cell wall especially above $200^{\circ} \mathrm{C}$ and above $0.09 \mathrm{MPa}$.

\section{Tensile Creep Test Rigs}

Mills-Brown et al. (2013) [90] studied the development of tensile creep test rig in elevated temperature environment. The test evaluated the capability of composite laminates up to $1000^{\circ} \mathrm{C}$ along long-term loading period. The test equipment, such as passive grip and creep fixture, was used to assist thin, small, and narrow to centre shaped coupons (Figure 10). The grips in the test were designed to resist hot condition environment to remove thermal gradient problems associated with cold grips. The material applied to build the grip component was Nickel alloy, specifically Inconel 718 grade. From Figure 11, the grips comprised of the main grip attachment with an oversized cut-out for the coupon to be inserted. Moreover, centring inserts were placed on either side of the coupon once in the grip before insertion of retaining plate to reduce associated stress concentrations from specimen cut-outs. The experiment implemented the use of optimal strain measurement equipment along the blinds to avoid interference from the rear emitter. Based on the results obtained in the paper, the test rig design was appropriate for both ceramic and polymer matrix composites, since they were incorporated with control mechanism. From the experiments conducted on the test rig, the polysialate composite failure strain increased from approximately 1.0-1.3\%. Moreover, strength decreased from $288 \mathrm{MPa}$ to $213 \mathrm{MPa}$, which ultimately reduced the stiffness of the material from $32.0 \mathrm{GPa}$ to $17.3 \mathrm{GPa}$ in temperature range of $0-760{ }^{\circ} \mathrm{C}$.

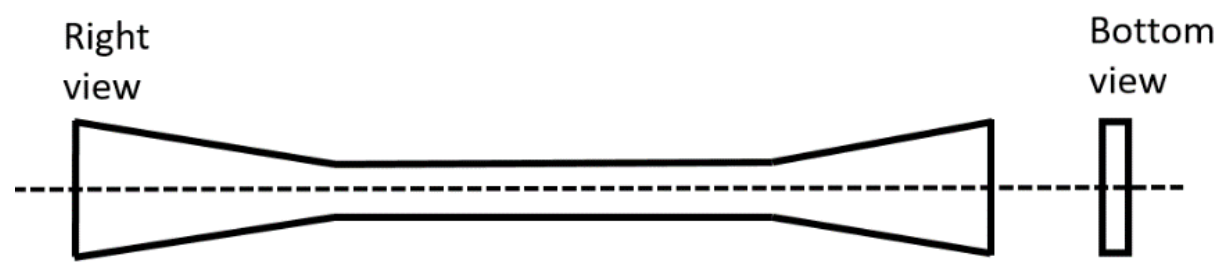

Figure 10. Tensile coupon shape and size. 


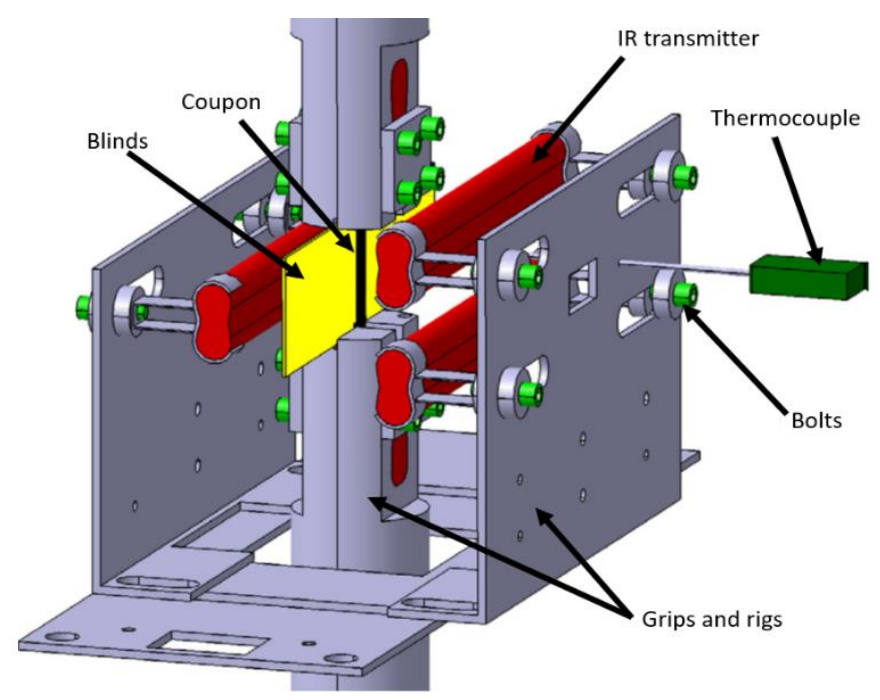

Figure 11. Final grip assembly and test setup for creep tensile test in elevated temperature.

Other than that, Jorik et al. (2019) [91] studied the design of the novel tensile creep arrangement of the long-term creep performance of composite laminate. The study implemented different load conditions and constant temperatures of $40{ }^{\circ} \mathrm{C}, 60{ }^{\circ} \mathrm{C}, 80^{\circ} \mathrm{C}$, and $100{ }^{\circ} \mathrm{C}$ on polycarbonate. As shown in Figure 12, the creep testing equipment consisted of a clamping system (lower and upper clamps) to grip the specimen inside the thermal chamber. Each clamp consisted of a single block clamp body and two jaws bolted to it. This firm design inhibited the system from unwanted vibrations and yielding under load. On top of that, the lower clamp was connected by ball bearing to a solid frame in order to prevent torsion on sample, and permitted the system to move freely during the clamping process. The clamping body was tightened by clamping screw. In addition, the whole system was made of stainless steel and the load applied in the system was controlled by actuators. In terms of temperature regulator, the temperature recorded by a thermocouple near the sample was used to regulate the heating element. The temperature chamber had an application range up to $170{ }^{\circ} \mathrm{C}$. Each chamber was equipped with its own temperature monitoring relay. The temperature regulation based on the temperature signal of the thermocouple was carried out automatically by the computer software, LabVIEW control program. The finding depicted that the primary creep region affected the crazing on tension creep. In addition, the results of stress activated process from secondary creep were elaborated with Ree-Eyring law using a single activation volume. The study also found the temperature-dependent properties by executing an Arrhenius equation with an activation energy value in conjunction with the energy of $\mathrm{C}-\mathrm{C}$ bonds scission. Non-recoverable deformations happened through temperature possessed during the steady state creep process.

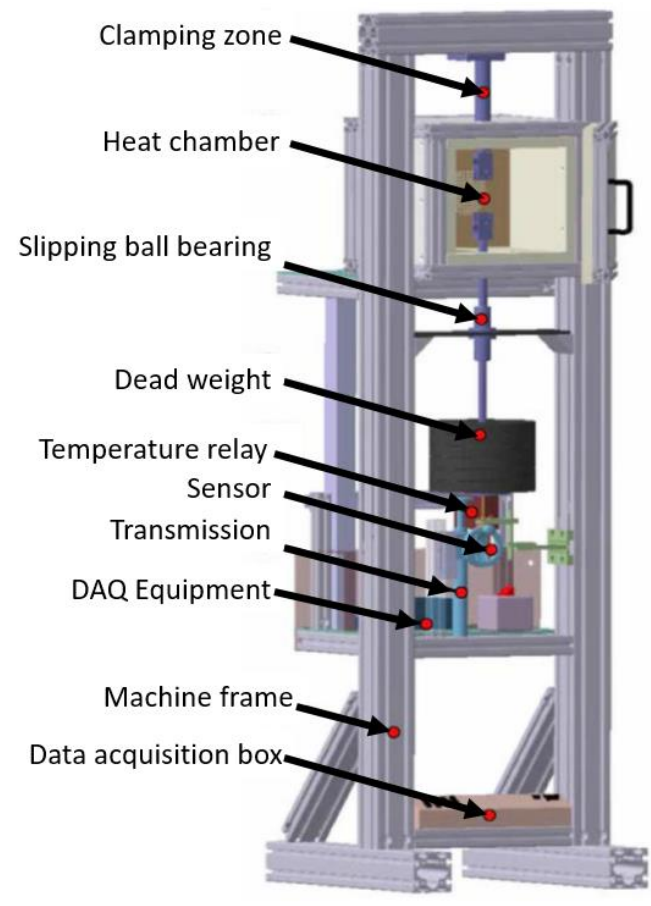

Figure 12. Final CAD drawing of grip assembly of tensile creep test rig. 
D'Antonio and Pisani (2019) [92] studied the long-term behaviour of GFRP reinforcing bars used in reinforced concrete member by evaluating the creep and relaxation properties. A complete test cycle was taken up about 1000 hours and 2000 hours for selected sets only. Around twenty-six (26) rebars of GFRP composite were produced from a single batch production. Five different stresses were applied, namely 10\%, 20\%, 40\%, 60\%, and 80\%, from ultimate tensile strength of the rebar. The test machine was incorporated with extensometer $400 \mathrm{~mm}$, which was attached on the specimen. The strain measurement was continuously recorded directly via the controlling software. This process compensated the elongations of the specimen by moving a weight on a lever arm of the testing machine (Figure 13). The machine was placed in laboratory environment with controlled temperature $\left(20^{\circ} \mathrm{C}\right)$ and humidity $(\mathrm{RH}=50 \%)$. The outcomes displayed that a new relaxation and creep formulas have been projected, with adopted linear logarithmic equation. This explained the bar experience linear viscoelastic behaviour under service load, which was less than $40 \%$ from the maximum tensile strength. Moreover, the long-term tests did not affect the strength and elastic modulus of the GFRP bars when the initial applied stress did not exceed $60 \%$ of stress level. Additionally, for both relaxation and creep tests, $80 \%$ completely failed in less than 8 hours of operation

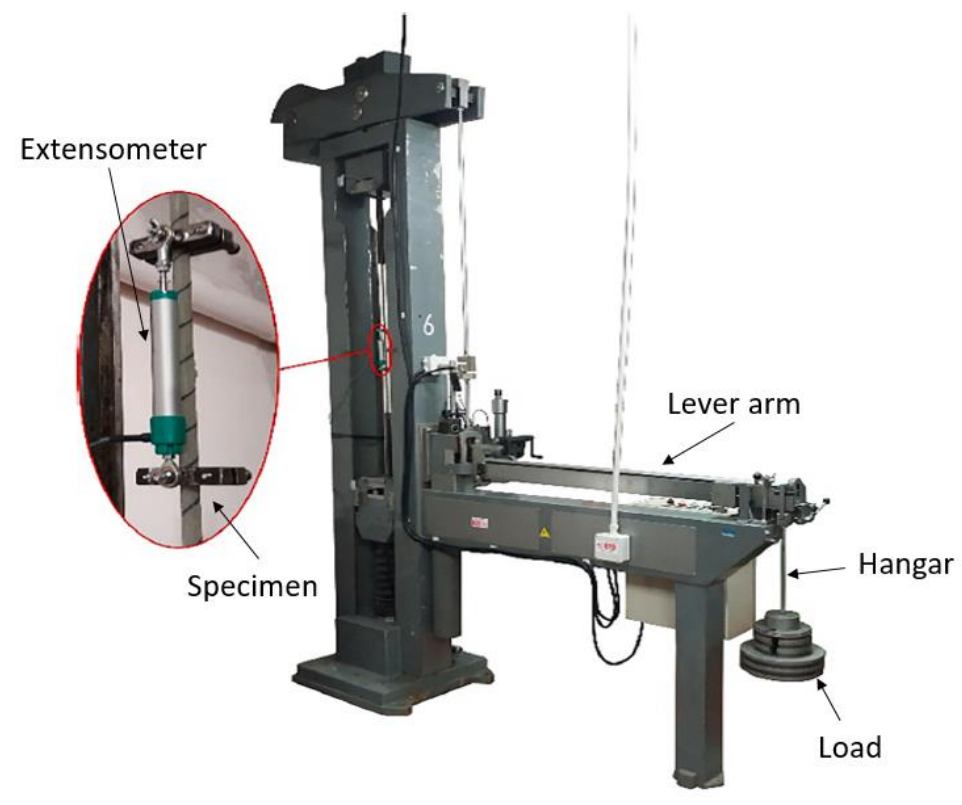

Figure 13. Creep tensile testing machine for composite rebar.

\section{Flexural Creep Test Rigs}

A study on creep flexural test of the GFRP pultruded beam in both short-term and long-term creep modes was done by Loni et al. (2013) [93]. Around twenty (20) specimens of pultruded GFRP have been carried out in four-point flexural mode. The test was performed with two identical vertical loads with intensity of $26 \%, 35 \%$, and $45 \%$ from ultimate flexural load in each set of experiment. The experiment was planned based on European Standard EN ISO 14125:1998 [94]. Figure 14 depicts a specific custom-made apparatus. The test rig was made up of C-channel steel to form metallic frame. In terms of the support span, it was assembled with $48 \mathrm{~mm}$ in diameter of cylindrical tubes. For a single run of experiment, 20 repetitions can be done simultaneously. In terms of size of specimens, it can be either $600 \mathrm{~mm}$ or $800 \mathrm{~mm}$. The load was applied via levers, which can multiply the weight by a factor of 7 . Each lever was loaded at its end by metallic plates of known weight of $4 \mathrm{~kg}$. The application of metallic plate was implemented and carried by hydraulic piston through hangar to the beam. In addition, the environment of the room was monitored and controlled by sensors (heaters, infrared sensor, and moisture sensor) to ensure a homogenous temperature field. At the end of the experiment, each data deflection and deformation was recorded via data acquisition system software supported by LabVIEW. According to the experimental results, the Findley power law equation was well fitted to GFRP pultruded specimen since the model implemented the time exponent which was independent to the temperature and stress. Additionally, the pure and shear bending states have set their reference state at $26 \%$ of the ultimate load, and $26^{\circ} \mathrm{C}$ in order to conduct timetemperature stress superposition (TTSSP) mode. In this procedure, the creep life prediction obtained for the material was around 11 years for pure bending, and 6.5 years for shear bending mode in a 24-hour test operation. Furthermore, the experiment verified that the master curve of TTSSP forecasted the viscoelastic behaviour well in long-term period. This indicates that the principle can be a guide in order to predict conventional creep method for other materials and conditions. 

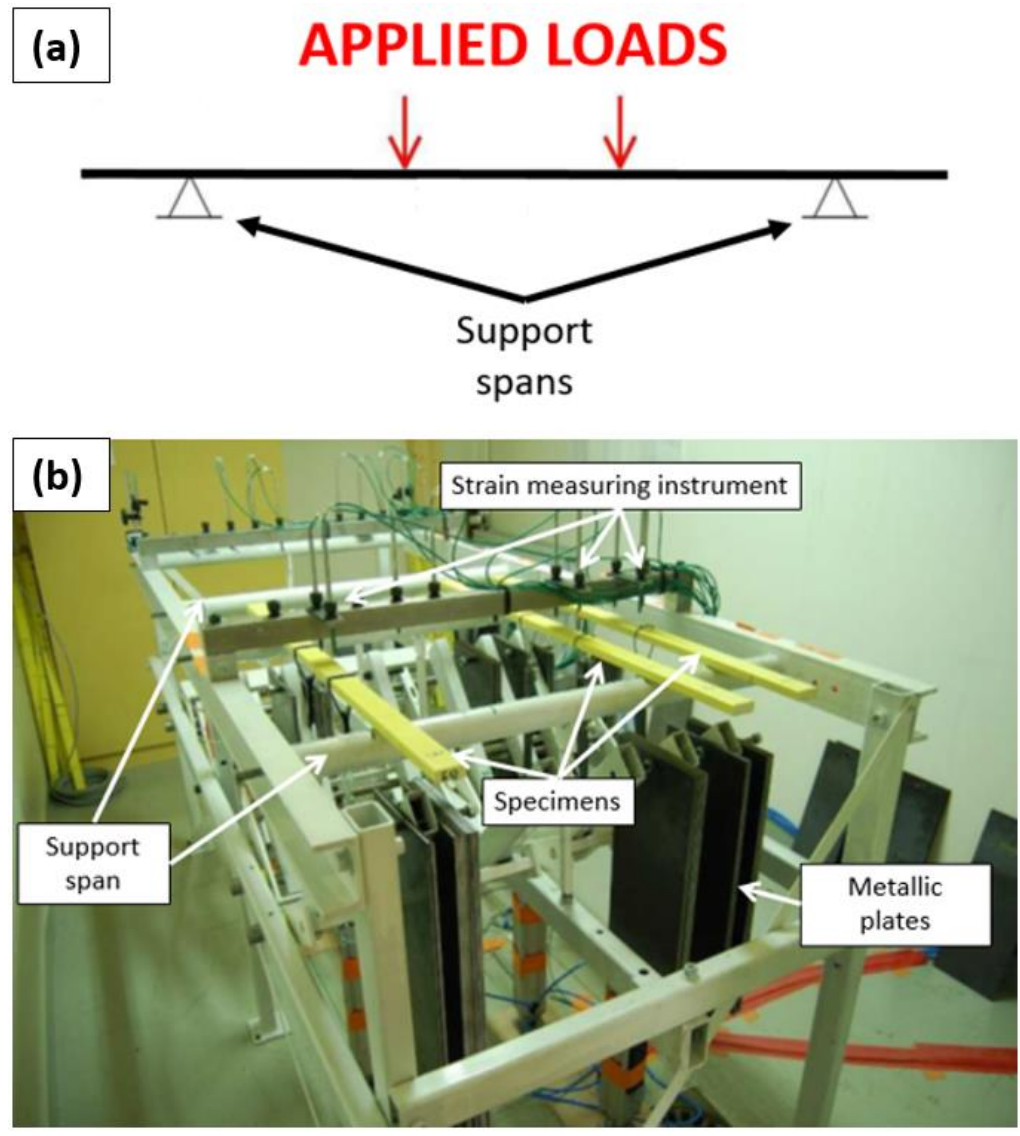

Figure 14. (a) Schematic diagram of application loadings; and (b) four point bending creep jig.

Fu et al. (2020) [51] also looked into the comparison of flexural creep properties coextruded composites (CEC) and laminated veneer lumber (LVL). The CEC was made up of core-shell structure as LVL and wood-plastic composites as shell layer. The test was implemented with three-point bending testing equipment to assess the creep properties. The equipment in Figure 15 was completed by two frames to carry two samples at a constant load in single period cycle (1500 hours). On top of that, the sample was loaded with iron frames welded by iron pipe with plastic bucket filled sand. The deflection of the specimen was recorded by dial gauge directly connected to a magnetic base. The extensometer was perfectly aligned at flat area of the roller (loading nose). The test was assessed at three-load levels, which are 30\%, 40\%, and $50 \%$ from the average ultimate flexural strength. The finding showed that Findley power law model was suitable for these experimental data compared to Burgers model and Norton-Bailey model to describe the creep pattern of CEC and LVL. In addition, the results also highlighted that CEC was highly potential to be used as durable material in heavy structural application.

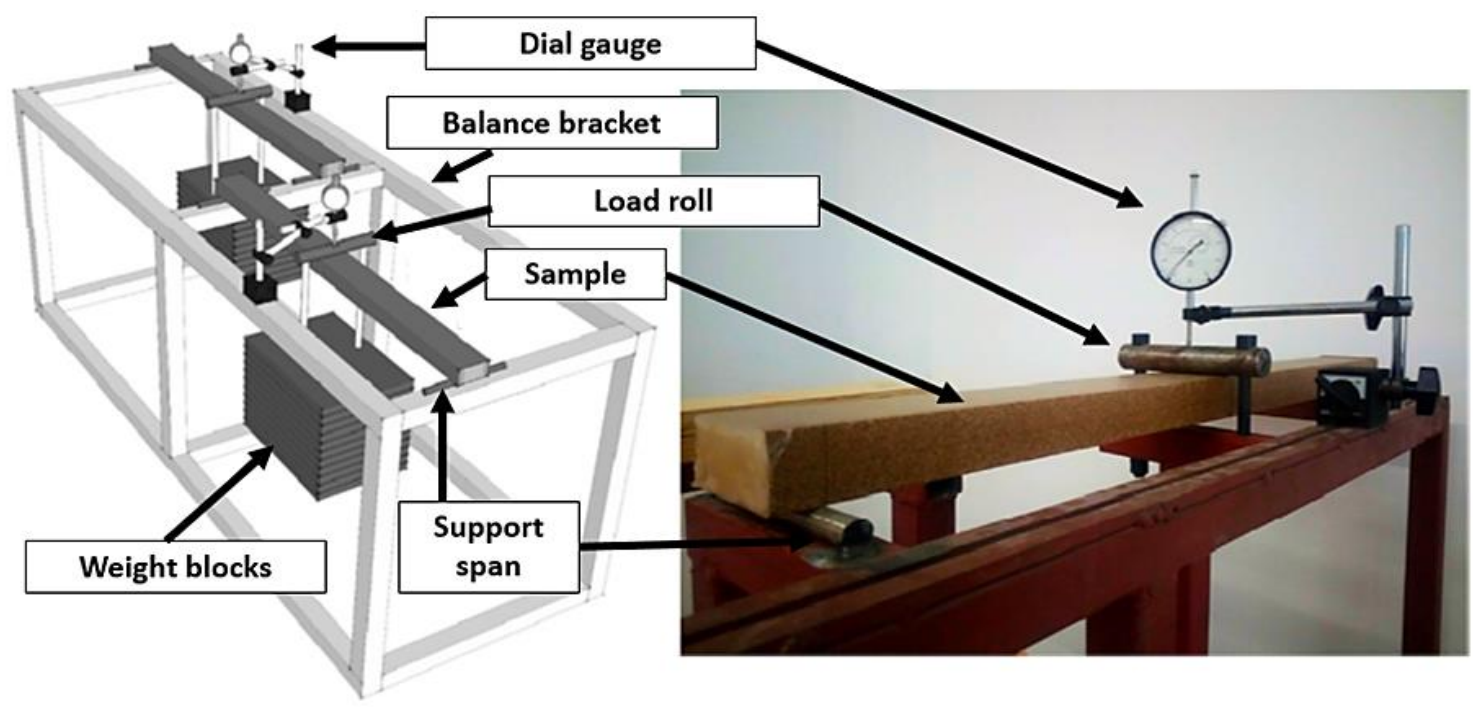

Figure 15. Flexural creep test rig setup for CEC and LVL specimens. 


\section{CONCLUSIONS}

The development of a new test rig to evaluate the creep life is very useful to understand the behaviour of a full-scale cross arm's creep and mechanical properties. To achieve this data, a test rig has to be designed which can aid in characterising these parameters. More specifically, a creep test rig which can perform cantilever beam mode creep test for actual sized cross arms needs to be developed for a more realistic investigation. The following major findings are concluded from the literature:

- The creep experimental operations are divided into two main approaches, conventional method and accelerated method, in order to estimate the creep behaviors and life estimation of a cantilever beam structure.

- Most anisotropic materials such as wood and composite structures experience creep strain depending on the humidity, temperature, and the stress level, which are exposed to them. The higher the humidity, temperature, and stress concentration applied to a material, the higher the creep degradation exposed to them.

- Numerical analysis for creep can also be described either into physical model (Burgers model) or empirical model (Findley's Power law and Norton-Bailey model) to verify and elaborate the creep data obtained from the experiment.

- The mechanics of cantilever beam directly involves the concept of moments, forces, and deflection in order to visualize the strength of material of the beam structure

- Three modes of creep tests are widely used by researchers, namely compression, tensile, and flexural. These techniques examine the creep properties with different mechanics approaches in order to analyze the capability of the material depending on their specific functions.

- In the end, a creep study on cantilever beam mode allows the specimen such as cross arm to experience a pure bending stress state with load occupied at the end. This technique aids the creep analysis to be broader, and has wider view in order to forecast the long-term properties as well as life estimation.

\section{ACKNOWLEDGMENTS}

The authors would like to thank Universiti Putra Malaysia (UPM) for the financial support provided through Geran Putra, UPM with VOT no. 9634000. The authors are very thankful to Department of Aerospace Engineering, Faculty of Engineering, UPM for providing facilities as well as Jabatan Perkhidmatan Awam (JPA) and Kursi Hajah Rahmah Nawawi for providing financial aids to the principal author to carry out this research project.

\section{REFERENCES}

[1] M. S. A. Bakar, D. Mohamad, Z. A. M. Ishak, Z. M. Yusof, and N. Salwi, "Durability control of moisture degradation in GFRP cross arm transmission line towers," AIP Conf. Proc., vol. 020027, no. November, 2018

[2] M. R. M. Asyraf, M. R. Ishak, S. M. Sapuan, and N. Yidris, "Conceptual design of multi-operation outdoor flexural creep test rig using hybrid concurrent engineering approach," J. Mater. Res. Technol., vol. 9, no. 2, pp. 2357-2368, Mar. 2020, doi: 10.1016/j.jmrt.2019.12.067

[3] I. M. Rawi and M. Z. A. Ab Kadir, "Investigation on the $132 \mathrm{kV}$ overhead lines lightning-related flashovers in Malaysia," in International Symposium on Lightning Protection, XIII SIPDA, 2015, pp. 239-243, doi: 10.1109/SIPDA.2015.7339293

[4] A. C. Liew, "Assessment of the lightning performance of quadruplecircuit transmission lines with steel and wooden crossarms," Electr. power Syst. Res., vol. 27, no. 2, pp. 91-97, 1993

[5] C. N. A. Jaafar, M. A. M. Rizal, and I. Zainol, "Effect of kenaf alkalization treatment on morphological and mechanical properties of epoxy / silica / kenaf composite," Int. J. Eng. Technol., vol. 7, pp. 258-263, 2018, doi: 10.14419/ijet.v7i4.35.22743

[6] C. N. A. Jaafar, I. Zainol, and M. A. M. Rizal, "Preparation and characterisation of epoxy / silica / kenaf composite using hand lay-up method," in 27th Scientific Conference of the Microscopy Society Malaysia (27th SCMSM 2018), 2018, pp. 2-6

[7] R. M. Shahroze, M. Chandrasekar, K. Senthilkumar, et al., "A review on the various fibre treatment techniques used for the fibre surface modification of the sugar palm fibres," in Seminar Enau Kebangsaan, 2019, no. 1, pp. 48-52

[8] I. M. Rawi, M. S. A. Rahman, M. Z. A. Ab Kadir, and M. Izadi, "Wood and fiberglass crossarm performance against lightning strikes on transmission towers," in International Conference on Power Systems Transient (IPST), 2017, pp. 1-6

[9] A. Syamsir, Z. A. M. Ishak, Z. M. Yusof, N. Salwi, and A. Nadhirah, "Durability control of UV radiation in glass fiber reinforced polymer (GFRP) - A review,” AIP Conf. Proc., vol. 2031, no. November, 2018, doi: 10.1063/1.5066989

[10] Z. Itam, Z. A. M. Ishak, Z. M. Yusof, N. Salwi, and M. Zainoodin, "Effect on the temperature behavior of glass fiber reinforced polymer (GFRP) in various application - A review," AIP Conf. Proc., vol. 2031, no. November, pp. 1-5, 2018, doi: $10.1063 / 1.5066982$

[11] Q. Ahsan, T. S. S. Carron, and Z. Mustafa, "On the use of nano fibrillated kenaf cellulose fiber as reinforcement in polylactic acid biocomposites,” J. Mech. Eng. Sci., vol. 13, no. 2, pp. 4970-4988, 2019, doi: 10.15282/jmes.13.2.2019.15.0412

[12] R. A. Ilyas, S. M. Sapuan, A. Atiqah, et al., "Sugar palm ( Arenga pinnata [ Wurmb .] Merr ) starch films containing sugar palm nanofibrillated cellulose as reinforcement: Water barrier properties," Polym. Compos., no. July, pp. 1-9, 2019, doi: $10.1002 /$ pc. 25379 
[13] M. R. M. Asyraf, M. R. Ishak, S. M. Sapuan, and N. Yidris, "Conceptual design of creep testing rig for full-scale cross arm using TRIZ-Morphological chart-analytic network process technique,” J. Mater. Res. Technol., vol. 8, no. 6, pp. 5647-5658, Oct. 2019, doi: 10.1016/j.jmrt.2019.09.033

[14] A. M. N. Maisara, R. A. Ilyas, S. M. Sapuan, et al., "Effect of fibre length and sea water treatment on mechanical properties of sugar palm fibre reinforced unsaturated polyester composites," Int. J. Recent Technol. Eng., vol. 8, no. 2S4, pp. 510-514, 2019, doi: 10.35940/ijrte.b1100.0782s419

[15] A. Atiqah, M. Jawaid, S. M. Sapuan, et al., "Physical and thermal properties of treated sugar palm/glass fibre reinforced thermoplastic polyurethane hybrid composites," J. Mater. Res. Technol., no. July, Jul. 2019, doi: 10.1016/j.jmrt.2019.06.032

[16] R. A. Ilyas and S. M. Sapuan, "The preparation methods and processing of natural fibre bio-polymer composites," Curr. Org. Synth., vol. 16, no. 8, pp. 1068-1070, Jan. 2020, doi: 10.2174/157017941608200120105616

[17] R. A. Ilyas, S. M. Sapuan, and M. R. Ishak, "Isolation and characterization of nanocrystalline cellulose from sugar palm fibres (Arenga Pinnata)," Carbohydr. Polym., vol. 181, pp. 1038-1051, Feb. 2018, doi: 10.1016/j.carbpol.2017.11.045

[18] R. A. Ilyas, S. M. Sapuan, M. R. Ishak, and E. S. Zainudin, "Development and characterization of sugar palm nanocrystalline cellulose reinforced sugar palm starch bionanocomposites," Carbohydr. Polym., vol. 202, pp. 186-202, Dec. 2018, doi: 10.1016/j.carbpol.2018.09.002

[19] R. A. Ilyas, S. M. Sapuan, R. Ibrahim, et al., "Thermal, biodegradability and water barrier properties of bio-nanocomposites based on plasticised sugar palm starch and nanofibrillated celluloses from sugar palm fibres," J. Biobased Mater. Bioenergy, vol. 14, pp. 1-13, 2020, doi: 10.1166/jbmb.2020.1951

[20] R. A. Ilyas, S. M. Sapuan, R. Ibrahim, et al., "Production, processes and modification of nanocrystalline cellulose from agrowaste: A review," in Nanocrystalline Materials, IntechOpen, 2019, pp. 3-32, doi: 10.5772/intechopen.87001

[21] M. S. N. Atikah, R. A. Ilyas, S. M. Sapuan, et al., "Degradation and physical properties of sugar palm starch / sugar palm nanofibrillated cellulose bionanocomposite," Polimery, vol. 64, no. 10, pp. 27-36, 2019, doi: 10.14314/polimery.2019.10.5

[22] R. A. Ilyas, S. M. Sapuan, R. Ibrahim, et al., "Effect of sugar palm nanofibrillated cellulose concentrations on morphological, mechanical and physical properties of biodegradable films based on agro-waste sugar palm (Arenga pinnata (Wurmb.) Merr) starch,” J. Mater. Res. Technol., vol. 8, no. 5, pp. 4819-4830, Sep. 2019, doi: 10.1016/j.jmrt.2019.08.028

[23] N. M. Nurazzi, A. Khalina, S. M. Sapuan, and R. A. Ilyas, "Mechanical properties of sugar palm yarn / woven glass fiber reinforced unsaturated polyester composites : effect of fiber loadings and alkaline treatment," Polimery, vol. 64, no. 10, pp. 12-22, 2019, doi: 10.14314/polimery.2019.10.3

[24] S. M. Sapuan, "Development of Sugar Palm-Based Products: A Community Project," in Sugar Palm Biofibers, Biopolymers, and Biocomposites, 1st ed., Boca Raton, FL : CRC Press, 2018, pp. 245-266, doi: 10.1201/9780429443923-12

[25] H. Abral, J. Ariksa, M. Mahardika, et al., "Transparent and antimicrobial cellulose film from ginger nanofiber," Food Hydrocoll., vol. 98, p. 105266, Jan. 2020, doi: 10.1016/j.foodhyd.2019.105266

[26] A. M. N. Azammi, R. A. Ilyas, S. M. Sapuan, et al., "Characterization studies of biopolymeric matrix and cellulose fibres based composites related to functionalized fibre-matrix interface," in Interfaces in Particle and Fibre Reinforced Composites, 1st ed., no. November, London: Elsevier, 2020, pp. 29-93, doi: 10.1016/B978-0-08-102665-6.00003-0

[27] H. A. Aisyah, M. T. Paridah, S. M. Sapuan, et al., "Thermal properties of woven kenaf/carbon fibre-reinforced epoxy hybrid composite panels," Int. J. Polym. Sci., vol. 2019, no. December, pp. 1-8, Dec. 2019, doi: 10.1155/2019/5258621

[28] M. D. Hazrol, S. M. Sapuan, R. A. Ilyas, M. L. Othman, and S. F. K. Sherwani, "Electrical properties of sugar palm nanocrystalline cellulose, reinforced sugar palm starch nanocomposites," Polimery, vol. 55, no. 5, pp. 33-40, 2020, doi: 10.14314/polimery.2020.5.5

[29] A. N. Johari, M. R. Ishak, Z. Leman, et al., "Fabrication and cut-in speed enhancement of savonius vertical axis wind turbine (SVAWT) with hinged blade using fiberglass composites," in Seminar Enau Kebangsaan, 2019, no. 1997, pp. 978-983

[30] S. Ashwindran, A. A. Azizuddin, and A. N. Oumer, "Computational fluid dynamic (CFD) of vertical-axis wind turbine: Mesh and time-step sensitivity study," J. Mech. Eng. Sci., vol. 13, no. 3, pp. 5604-5624, 2019, doi: 10.15282/jmes.13.3.2019.24.0450

[31] N. Mazani, S. M. Sapuan, M. L. Sanyang, A. Atiqah, and R. A. Ilyas, "Design and fabrication of a shoe shelf from kenaf fiber reinforced unsaturated polyester composites," in Lignocellulose for Future Bioeconomy, no. 2000, Elsevier Inc., 2019, pp. 315332, doi: 10.1016/b978-0-12-816354-2.00017-7

[32] Z. Shanti Kiran, V. Suresh Babu, and K. V. L. Soma Sekhar, "Study of the microhardness and erosive wear behavior of organomodified nanoclay filled glass-epoxy composites and optimization," J. Mech. Eng. Sci., vol. 13, no. 2, pp. 4794-4815, 2019, doi: 10.15282/jmes.13.2.2019.03.0400

[33] M. N. Norizan, K. Abdan, R. A. Ilyas, and S. P. Biofibers, "Effect of fiber orientation and fiber loading on the mechanical and thermal properties of sugar palm yarn fiber reinforced unsaturated polyester resin composites," Polimery, vol. 65, no. 2, pp. 34-43, 2020, doi: 10.14314/polimery.2020.2.5

[34] N. M. Nurazzi, A. Khalina, S. M. Sapuan, et al., "Thermal properties of treated sugar palm yarn/glass fiber reinforced unsaturated polyester hybrid composites,” J. Mater. Res. Technol., vol. 9, no. 2, pp. 1606-1618, Mar. 2020, doi: 10.1016/j.jmrt.2019.11.086

[35] D. Mohamad, A. Syamsir, S. Beddu, et al., "Numerical study of composite fiberglass cross arms under statics loading and improvement with sleeve installation," IOP Conf. Ser. Mater. Sci. Eng., vol. 530, p. 012027, 2019, doi: 10.1088/1757$899 X / 530 / 1 / 012027$ 
[36] D. Mohamad, A. Syamsir, S. N. Sa'don, et al., "Stacking sequence effects on performance of composite laminate structure subjected to multi-axial quasi-static loading stacking sequence," IOP Conf. Ser. Mater. Sci. Eng., vol. 530, pp. 1-6, 2019, doi: 10.1088/1757-899X/530/1/012030

[37] D. Mohamad, A. Syamsir, Z. Itam, et al., "Numerical simulation on the statics deformation study of composite cross arms of different materials and configurations," IOP Conf. Ser. Mater. Sci. Eng., vol. 530, no. 1, 2019, doi: 10.1088/1757$899 \mathrm{X} / 530 / 1 / 012028$

[38] W. Ashraf, M. R. Ishak, M. Y. M. Zuhri, et al., "Investigation of different facesheet materials on compression properties of honeycomb sandwich composite," in Seminar Enau Kebangsaan, 2019, pp. 129-132

[39] M. F. Younes and M. A. Abdel Rahman, "Tensile relaxation behaviour for multi layes fiberglass fabric/epoxy composite," Eur. J. Mater. Sci., vol. 3, no. 1, pp. 1-13, 2016

[40] A. Anand, P. Banerjee, R. K. Prusty, and B. Chandra Ray, "Lifetime prediction of nano-silica based glass fibre/epoxy composite by time temperature superposition principle," IOP Conf. Ser. Mater. Sci. Eng., vol. 338, no. 1, 2018, doi: 10.1088/1757899X/338/1/012020

[41] A. Nadhirah, D. Mohamad, M. Zainoodin, et al., "Properties of fiberglass crossarm in transmission tower - A review," Prop. fiberglass crossarm Transm. tower - a Rev., vol. 12, no. 24, pp. 15228-15233, 2017

[42] M. R. M. Asyraf, M. R. Ishak, S. M. Sapuan, et al., "Creep test rig for full-scale composite crossarm: simulation modelling and analysis," in Seminar Enau Kebangsaan, 2019, pp. 34-38

[43] H. Kumawat, "Use of graphene-based composite pipe materials for transportation of oil and gas," ASME 2015 India Int. Oil Gas Pipeline Conf. IOGPC 2015, 2015, doi: 10.1115/IOGPC2015-7952

[44] M. R. M. Asyraf, M. R. Ishak, M. R. Razman, and M. Chandrasekar, "Fundamentals of creep, testing methods and development of test rig for the full-scale crossarm: a review," J. Teknol., vol. 81, no. 4, pp. 155-164, Jun. 2019, doi: 10.11113/jt.v81.13402

[45] N. Sun and C. E. Frazier, "Time/temperature equivalence in the dry wood creep response," Holzforschung, vol. 61, no. 6, pp. 702-706, 2007, doi: 10.1515/HF.2007.114

[46] Y. Taniguchi, K. Ando, and H. Yamamoto, "Determination of three-dimensional viscoelastic compliance in wood by tensile creep test," J. Wood Sci., vol. 56, no. 1, pp. 82-84, 2010, doi: 10.1007/s10086-009-1069-6

[47] M. Tajvidi, R. H. Falk, and J. C. Hermanson, "Time-temperature superposition principle applied to a kenaf-fiber/high- density polyethylene composite,” J. Appl. Polym. Sci., vol. 97, no. 5, pp. 1995-2004, 2005, doi: 10.1002/app.21648

[48] B. Ponsot, D. Valentin, and A. R. Bunsell, "The effects of time, temperature and stress on the long-term behaviour of CFRP," Compos. Sci. Technol., vol. 35, no. 1, pp. 75-94, 1989, doi: 10.1016/0266-3538(89)90071-7

[49] Z. Zhang, J. L. Yang, and K. Friedrich, “Creep resistant polymeric nanocomposites,” Polymer, vol. 45, no. 10, pp. 3481-3485, May 2004, doi: 10.1016/j.polymer.2004.03.004

[50] D. Basaid, C. Aribi, J. Kari, A. Benmounah, and B. Safi, "A comparative study of the creep behavior of laminated composites: Effect of type of fiber and matrix," Sci. Res. Essays, vol. 12, no. 6, pp. 59-68, 2017, doi: 10.5897/sre2017.6492

[51] H. Fu, M. Dun, H. Wang, et al., "Creep response of wood flour-high-density polyethylene/laminated veneer lumber coextruded composites," Constr. Build. Mater., vol. 237, p. 117499, 2020, doi: 10.1016/j.conbuildmat.2019.117499

[52] H. Chandekar and V. Chaudhari, "Flexural creep behaviour of jute polypropylene composites," IOP Conf. Ser. Mater. Sci. Eng., vol. 149, no. 1, pp. 1-7, 2016, doi: 10.1088/1757-899X/149/1/012107

[53] V. S. Chevali, D. R. Dean, and G. M. Janowski, "Flexural creep behavior of discontinuous thermoplastic composites: Nonlinear viscoelastic modeling and time-temperature-stress superposition," Compos. Part A Appl. Sci. Manuf., vol. 40, no. 6-7, pp. 870-877, 2009, doi: 10.1016/j.compositesa.2009.04.012

[54] S. Kumar Ghosh, R. K. Prusty, D. K. Rathore, and B. C. Ray, "Creep behaviour of graphite oxide nanoplates embedded glass fiber/epoxy composites: Emphasizing the role of temperature and stress," Compos. Part A Appl. Sci. Manuf., vol. 102, pp. 166177, 2017, doi: 10.1016/j.compositesa.2017.08.001

[55] N. Buratti and C. Mazzotti, "Creep testing methodologies and results interpretation," in RILEM Bookseries, 2017, vol. 14, pp. 13-24, doi: 10.1007/978-94-024-1001-3_2

[56] P. D. Nieuwoudt and W. P. Boshoff, The Time-Dependant Pull-Out Behaviour of Hooked Steel Fibres. 2016

[57] D. Daviau-Desnoyers, J.-P. Charron, B. Massicotte, P. Rossi, and J.-L. Tailhan, "Creep behavior of a SFRC under service and ultimate bending loads," in Creep Behaviour in Cracked Sections of Fibre Reinforced Concrete, Springer, 2017, pp. 223-235

[58] A. Hao, Y. Chen, and J. Y. Chen, "Creep and recovery behavior of kenaf/polypropylene nonwoven composites," J. Appl. Polym. Sci., vol. 131, no. 17, pp. 8864-8874, 2014, doi: 10.1002/app.40726

[59] M. Hadid, B. Guerira, M. Bahri, and K. Zouani, "The creep master curve construction for the polyamide 6 by the stepped isostress method," Mater. Res. Innov., vol. 18, no. sup6, pp. S6-336-S6-339, 2014, doi: 10.1179/1432891714z.0000000001022

[60] S. C. Yen and F. L. Williamson, "Accelerated characterization of creep response of an off-axis composite material," Compos. Sci. Technol., vol. 38, no. 2, pp. 103-118, 1990, doi: 10.1016/0266-3538(90)90001-L

[61] M. R. M. Asyraf, M. R. Ishak, S. M. Sapuan, and N. Yidris, "Woods and composites cantilever beam: A comprehensive review of experimental and numerical creep methodologies," J. Mater. Res. Technol., 2020, doi: 10.1016/j.jmrt.2020.01.013

[62] W. N. Findley and F. A. Davis, Creep and relaxation of nonlinear viscoelastic materials. Courier Corporation, 2013

[63] I. M. Ward and J. Sweeney, Mechanical properties of solid polymers. John Wiley \& Sons, 2012 
[64] V. A. Alvarez, J. M. Kenny, and A. Vázquez, "Creep behavior of biocomposites based on sisal fiber reinforced cellulose derivatives/starch blends," Polym. Compos., vol. 25, no. 3, pp. 280-288, 2004, doi: 10.1002/pc.20022

[65] P. K. Chandra and P. J. do A. Sobral, "Calculation of viscoelastic properties of edible films: Application of three models," Ciência e Tecnol. Aliment., vol. 20, no. 2, pp. 250-256, 2006, doi: 10.1590/s0101-20612000000200021

[66] W. N. Findley, J. S. Lai, K. Onaran, and R. M. Christensen, "Creep and relaxation of nonlinear viscoelastic materials with an introduction to linear viscoelasticity," J. Appl. Mech., vol. 44, no. 2, p. 364, 2010, doi: 10.1115/1.3424077

[67] J. L. Yang, Z. Zhang, A. K. Schlarb, and K. Friedrich, "On the characterization of tensile creep resistance of polyamide 66 nanocomposites. Part II: Modeling and prediction of long-term performance," Polymer (Guildf)., vol. 47, no. 19, pp. 67456758, 2006, doi: 10.1016/j.polymer.2006.07.060

[68] Y. Jia, K. Peng, X. Gong, and Z. Zhang, "Creep and recovery of polypropylene/carbon nanotube composites," Int. J. Plast., vol. 27, no. 8, pp. 1239-1251, 2011

[69] A. Plaseied and A. Fatemi, "Tensile creep and deformation modeling of vinyl ester polymer and its nanocomposite," J. Reinf. Plast. Compos., vol. 28, no. 14, pp. 1775-1788, 2009

[70] D. Tscharnuter and A. Muliana, "Nonlinear response of viscoelastic polyoxymethylene (POM) at elevated temperatures," Polymer (Guildf)., vol. 54, no. 3, pp. 1208-1217, 2013

[71] M. I. M. Ahmad, J. L. Curiel Sosa, and J. A. Rongong, "Characterisation of creep behaviour using the power law model in copper alloy," J. Mech. Eng. Sci., vol. 11, no. 1, pp. 2503-2510, 2017, doi: 10.15282/jmes.11.1.2017.9.0230

[72] R. J. Hoyle, M. C. Griffith, and R. Y. Itani, "Primary creep in Douglas-fir beams of commercial size and quality," Wood Fiber Sci., vol. 17, no. 3, pp. 300-314, 2007

[73] Y. Du, N. Yan, and M. T. Kortschot, "An experimental study of creep behavior of lightweight natural fiber-reinforced polymer composite/honeycomb core sandwich panels," Compos. Struct., vol. 106, pp. 160-166, 2013, doi: 10.1016/j.compstruct.2013.06.007

[74] J. F. Hunt, H. Zhang, and Y. Huang, "Analysis of cantilever-beam bending stress relaxation properties of thin wood composites," BioResources, vol. 10, no. 2, pp. 3131-3145, 2015, doi: 10.15376/biores.10.2.3131-3145

[75] M. R. M. Asyraf, M. R. Ishak, S. M. Sapuan, et al., "Evaluation of design and simulation of creep test rig for full-scale cross arm structure," Adv. Civ. Eng., 2020, doi: 10.1155/2019/6980918

[76] H. W. Liu, Mechanics of Materials. Beijing: China Machine Press, 2004

[77] M. Moutee, M. Fafard, Y. Fortin, and A. Laghdir, "Modeling the creep behavior of wood cantilever loaded at free end during drying," Wood Fiber Sci., vol. 37, no. 3, pp. 521-534, 2005

[78] G. Zhao, M. di Prisco, and L. Vandewalle, "Experimental investigation on uniaxial tensile creep behavior of cracked steel fiber reinforced concrete," Mater. Struct. Constr., vol. 48, no. 10, pp. 3173-3185, 2015, doi: 10.1617/s11527-014-0389-1

[79] S. Wong and R. Shanks, "Creep behaviour of biopolymers and modified flax fibre composites," Compos. Interfaces, vol. 15, no. 2-3, pp. 131-145, 2008, doi: 10.1163/156855408783810894

[80] A. A. A. Rashdi, S. M. Sapuan, M. M. H. M. Ahmad, and A. Khalina, "Water absorption and tensile properties of soil buried kenaf fibre reinforced unsaturated polyester composites (KFRUPC)," J. Food, Agric. Environ., vol. 7, no. 3-4, pp. 908-911, 2009

[81] M. Muthuvel, G. Ranganath, K. Janarthanan, and K. Sarinivasan, "Characterization study of jute and glass fiber reinforced hybrid composite material,” Int. J. Eng. Res. Technol., vol. 2, no. 4, pp. 335-344, 2013, doi: 10.1177/2393957514555052

[82] M. T. Mastura, S. M. Sapuan, M. R. Mansor, and A. A. Nuraini, "Conceptual design of a natural fibre-reinforced composite automotive anti-roll bar using a hybrid approach," Int. J. Adv. Manuf. Technol., vol. 91, no. 5-8, pp. 2031-2048, Jul. 2017, doi: 10.1007/s00170-016-9882-8

[83] N. M. Ishak, D. Sivakumar, and M. R. Mansor, "The application of TRIZ on natural fibre metal laminate to reduce the weight of the car front hood," J. Brazilian Soc. Mech. Sci. Eng., vol. 40, no. 2, pp. 1-12, 2018, doi: 10.1007/s40430-018-1039-2

[84] M. R. Mansor, S. M. Sapuan, and A. Hambali, "Conceptual design of kenaf polymer composites automotive spoiler using TRIZ and Morphology Chart methods,” vol. 761, pp. 63-67, 2015, doi: 10.4028/www.scientific.net/AMM.761.63

[85] M. R. M. Asyraf, M. Rafidah, M. R. Ishak, et al., "Integration of TRIZ, Morphological Chart and ANP method for development of FRP composite portable fire extinguisher," Polym. Compos., 2020, doi: 10.1002/pc.25587

[86] F. Rubino, A. Nisticò, F. Tucci, and P. Carlone, "Marine Application of Fiber Reinforced Composites: A Review," J. Mar. Sci. Eng., vol. 8, no. 1, p. 26, 2020, doi: 10.3390/jmse8010026

[87] A. Iqbal, A. Saeed, and A. Ul-Hamid, "A review featuring the fundamentals and advancements of polymer/CNT nanocomposite application in aerospace industry," Polym. Bull., 2020, doi: 10.1007/s00289-019-03096-0

[88] D. W. Scott and A.-H. Zureick, "Compression creep of a pultruded E-glass/vinylester composite," Compos. Sci. Technol., vol. 58, no. 8, pp. 1361-1369, Aug. 1998, doi: 10.1016/S0266-3538(98)00009-8

[89] J. Wang, X. Wang, Q. He, Y. Zhang, and T. Zhan, "Time-temperature-stress equivalence in compressive creep response of Chinese fir at high-temperature range," Constr. Build. Mater., vol. 235, p. 117809, 2020, doi: 10.1016/j.conbuildmat.2019.117809

[90] J. Mills-Brown, K. Potter, S. Foster, and T. Batho, "The development of a high temperature tensile testing rig for composite laminates," Compos. Part A Appl. Sci. Manuf., vol. 52, pp. 99-105, 2013, doi: 10.1016/j.compositesa.2013.04.009 
[91] S. Jorik, A. Lion, and M. Johlitz, "Design of the novel tensile creep experimental setup, characterisation and description of the long-term creep performance of polycarbonate," Polym. Test., vol. 75, pp. 151-158, 2019, doi: 10.1016/j.polymertesting.2019.01.023

[92] T. D’Antino and M. A. Pisani, “Long-term behavior of GFRP reinforcing bars," Compos. Struct., vol. 227, 2019, doi: 10.1016/j.compstruct.2019.111283

[93] S. Loni, I. Stefanou, and P. S. Valvo, "Experimental study on the creep behavior of GFRP pultruded beams," in AIMETA $2013-$ XXI Congresso Nazionale dell Associazione Italiana di Meccanica Teorica e Applicata, 2013, pp. 1-10

[94] EN ISO 14125-1998, "Fibre-reinforced plastic composites — Determination of flexural properties," 1988 